\title{
Volume 100 of the Journal of the Indian Institute of Science and 100 Years of the Latimer and Rodebush Paper on Hydrogen Bonding
}

\author{
E. Arunan*
}

I would like to thank Prof. T. N. Guru Row (former Editor of the Journal) and Prof. G. K. Ananthasuresh for giving me the opportunity to bring out a special issue of the Journal of Indian Institute of Science celebrating 100 years of the seminal paper on hydrogen bonding. A few years ago, Prof. Guru Row asked me to be a member of the Editorial board and we were discussing the issues for years 2018 and 2019. I realized that volume 100 will be produced in the year 2020 and suggested this possibility. Prof. Guru Row immediately agreed and Prof. Ananthasuresh who took over as the Editor in 2019 supported this wholeheartedly.

It is not an easy task to identify the person who suggested the concept of the hydrogen bonding first. Linus Pauling, who may be considered the most influential chemist from the twentieth century, credits the paper by Latimer and Rodebush published in 1920 as the first to mention hydrogen bonding. Pimentel and McClellan who authored the first book in this topic, titled 'The Hydrogen Bond' start their book with a quote from this paper. However, both the book by Pauling and the paper by Latimer and Rodebush refer to previous work by Huggins at the University of California, Berkeley. The undergraduate thesis submitted by Huggins in 1919 has been lost.

Pimentel and McClellan refer to the work of Nernst (1897), Werner (1903), and Moore and Winmill (1912), all of which discussed some form of hydrogen bonding between molecules. Moreover, they point out that Oddo and Puxeddu (1906) and Pfeiffer (1913) had discussed about 'intramolecular hydrogen bonding' through which two parts of the same molecule which are not directly bonded interact through a hydrogen bond. However, what Latimer and Roedbush wrote in 1920, quoted verbatim in my article in this issue elsewhere, is quite remarkable. Pimentel and McClellan wrote about this quote in their book published in 1960: It is an amazing fact that every word of their description remains acceptable in the contexture of chemical knowledge today. But the true historical importance of this statement derives from its pioneering invasion of a frontier of chemistry that even today presents uncertain footing to the chemist. This description remains accurate in 2020 !

Several authors who have made significant contributions to this field were invited to contribute for this special issue. Sixteen of them responded positively and this issue has their articles. All articles were peer reviewed before final acceptance. Among the authors, we have Profs. G. R. Desiraju and S. Schenier, who have both authored popular books on hydrogen bonding. They were both members of the IUPAC task group, along with me, which came up with a new definition of hydrogen bonding in 2011. One more member from that group, Prof. A. C. Legon has contributed as well. Profs. Desiraju, Scheiner, Legon and Prof. P. Politzer were members of the IUPAC task group that defined halogen bonding in 2013 and chalcogen bonding last year. Intermolecular bonding involving all main group elements has attracted enormous interest, particularly in this decade. This is discussed in many of the articles appearing in this special issue on hydrogen bonding.

This issue also has articles by Prof. Martin Suhm, Chairman of the Horizons in Hydrogen Bond Research Conference in 2011 at Göttingen, Germany, and Prof. Josè Fernandez, who would be the Chairman of the same conference in 2021 at Bilbao, Spain. Other authors include well-established researchers who have made significant contributions to this field from India: Prof. T. N. Guru Row, Prof. E. D. Jemmis, Prof. K. S. Viswanathan, Prof. S. J. Wategaonkar, Prof. T. Chakraborti, Prof. G. Mugesh and Prof. G. Naresh Patwari. This issue also features articles from young and accomplished researchers Prof. Himansu Biswal and Prof. Deepak Chopra.
${ }^{1}$ Department of Inorganic and Physical Chemistry, Indian Institute of Science, Bangalore 560012, India. *arunan@iisc.ac.in 
Articles cover both experimental and theoretical work in gas, liquid and solid phases. I do realize that we could have had many more authors who have made important contributions to this field.

I thank everyone from the offices of the Journal of the Indian Institute of Science and its publishers, Office of Communication from the Institute and Springer for their help and cooperation in bringing out this issue. It is hoped that this provides a nice summary of the history and present status of this important field. While it is always dangerous to predict the future of any field, I expect hydrogen bonding to remain an active area of research in the next century!

\section{Publisher's Note}

Springer Nature remains neutral with regard to jurisdictional claims in published maps and institutional affiliations.

Published online: 23 December 2019 